\title{
Dos enfoques energéticos que dominan y liberan el medioambiente en un proyecto de arquitectura
}

\author{
Jorge Camacho, Cristina \\ 1. Universidad de Alcalá de Henares, Escuela de Arquitectura, Área de Proyectos Arquitectónicos, Madrid
}

\begin{abstract}
Resumen
En un primer modelo energético, la cúpula geodésica de R.B.Fuller está formada por multitud de moléculas de aire en retícula que cubren el mayor espacio con el menor gasto de energía, como analiza mediante un modelo a escala menor en el proyecto "The Cardboard House". Debido a la influencia de los estudios de balística y de navegación, dentro del sistema sinergético opta por sustituir el aire, representado por un conjunto de corpúsculos blandos con cierta facilidad para la compresión, por el agua formado también por corpúsculos, pero duros como pequeñas bolas de acero con gran incapacidad para la compresión deslizando unas sobre otras al no poder absorber los esfuerzos tangenciales. En estos estudios, la geometría es una herramienta de trabajo que les sirve para prever y medir las inesperadas fuerzas de la naturaleza, calculando de antemano los sucesos energéticos en el tiempo. En un segundo modelo se establece una relación de contigüidad y no de asociación formal con la investigación sobre el automorfismo de R. Le Ricolais, a través de dos proyectos de infraestructuras adaptados a entornos distintos, uno aéreo "Sky-Rail" y otro acuático "Under Sea Transit", observando cómo cristales salinos y seres acuáticos sin gravedad inducen principios constructivos de nuevos sistemas estructurales como islas artificiales. Le Ricolais comenta que junto a la vida aparece el problema del crecimiento, y hasta ahora el hombre no ha sido capaz de construir máquinas capaces de crecer. Futuros proyectos de estructuras estudian alternar el uso de la última tecnología junto con el no-empleo de la misma, buscando un equilibrio entre un dominio del medioambiente y el abandono de todo control sobre el mismo.
\end{abstract}

Palabras clave: Cúpula geodésica, Richard B.Fuller, Robert Le Ricolais, Energía, Infraestructuras.

\begin{abstract}
In a first energy model, the geodecsic dome of R.B. Fuller, focused on the problem of how cover the maximum space with the minimum of energy, is made of many air molecules, such as "The Cardboard House" project where he explained the same items in a smaller scale. Because of the influence of the ballistic and navigation studies, the air solution, which is represented by several soft corpuscles and likely to support compressión strength, is replaced with water solution, which is made by corpuscles too, but such as small steel balls that are not be able to afford compression strength sliding one each other without taking up tangential stresses. In these studies, geometry is a working tool of prevention and measure of unexpected forces of nature, calculating in advance the energy events through time. In a second energy model, a conexión is established by contiguity and not by formal association with the principle of automorphism of R. Le Ricolais through two infrastuctural projects adapted to different enviroments, one is aereal "Sky-Rail" and the other aquatic "Under Sea Transit", showing how small glasses and microorganisms without gravity lead to building principles of new energy systems like artificial islands. Le Ricolais said that together with life comes the problem of growth, and until now man has not been capable of making machines that grow. About future structural projects, some thoughful approches for the future are alternated between the utilization of state-of-art technologies and no technology at all, between seeking total control of environment and abandoning all modes of control.
\end{abstract}

Key words: Geodesic dome, Richard B.Fuller, Robert Le Ricolais, Energy, Infraestructure. 


\section{Dos enfoques energéticos que dominan y liberan el medioambiente en un proyecto de arquitectura}

Como introducción a sus análisis energéticos, Buckminster Fuller define la geometría como la parte de las matemáticas que trata las propiedades y la medida de la extensión y la sinergia como un lenguaje metafórico que comunica experiencias usando conceptos geométricos que identifican la energía con un número. Igualmente define las matemáticas en función de la sinergia como una topología de la geometría que investiga la posición relativa de las figuras sin tener en cuenta deformaciones, semejanzas de medida, ángulos o longitudes, en combinación con otra geometría vectorial. La contigüidad en temas de energía dentro de distintos entornos con los proyectos "Sky-Rail" y "Under Sea Transit" de Robert Le Ricolais se produce a través del concepto de automorfismo o de repetición de un tema estructural que guía todo el proyecto, y de la inducción de principios constructivos en las formas orgánicas microscópicas dependientes del mundo submarino.

El estudio se aleja de las figuras elementales que sólo admiten la regla y el compás para las demostraciones y las conclusiones y emplea configuraciones geométricas con dos direcciones de expansión como la superficie helicoidal que resulta del giro y la traslación conjunta a lo largo de un eje. Por ello, no divide la geometría en vectores formados por tres partes que se encajan una a continuación de la otra, sino que funciona mediante conceptos métricos como la distancia y el ángulo que separan los elementos en capas y a través de conceptos temporales como la duración que mide el tiempo que transcurre entre el comienzo y el fin del desplazamiento. Como representación geométrica, el vector es una magnitud dirigida caracterizada por el modulo, la dirección y el sentido. Puede representar entidades abstractas como la velocidad, la aceleración, la fuerza, etc. y requiere no sólo un módulo (la cantidad), sino también una dirección (la recta que le contiene) y el sentido (la flecha); es decir, el vector necesita la figura de la flecha para poder distinguirse de un escalar. Se analizaran los modelos empleados para determinar cada línea de investigación.

\section{Los modelos energéticos de R.B.Fuller}

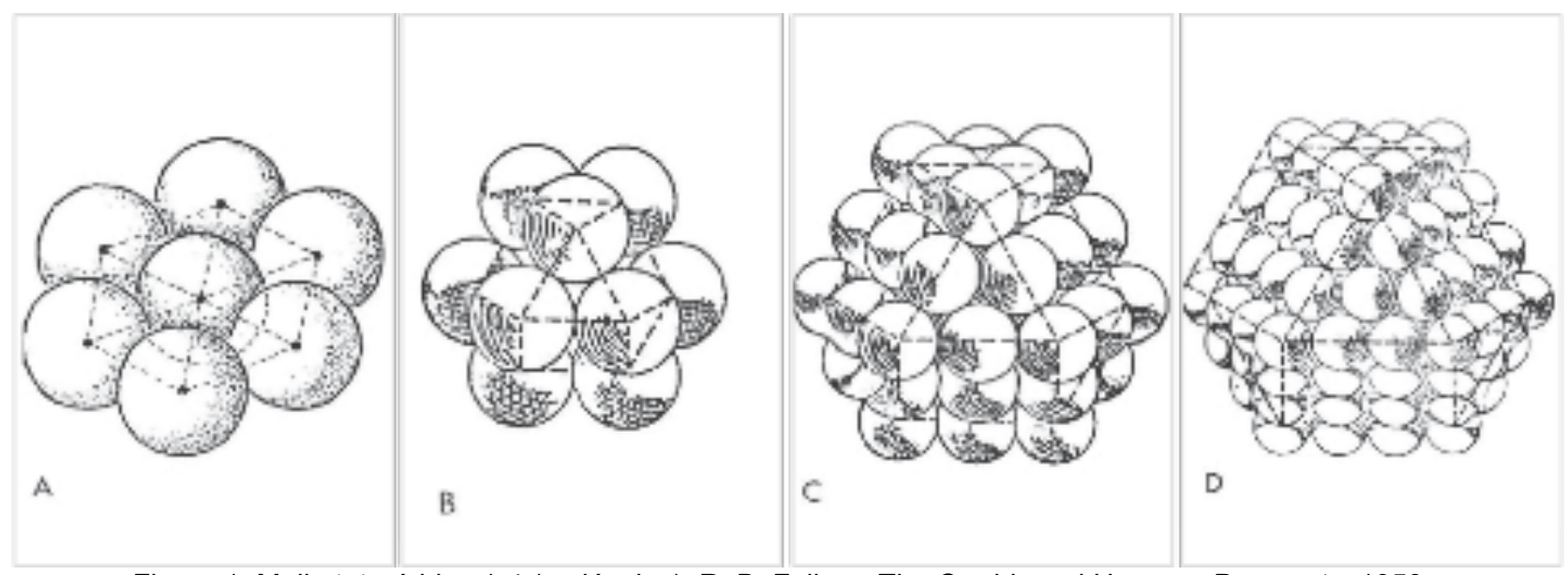

Figura 1. Malla tetraédrica 1-4 (moléculas). R. B. Fuller, «The Card-board House», Perspecta, 1953

En 1953, Buckminster Fuller analiza un proyecto de pequeña escala, unas viviendas prefabricadas realizado en la Universidad de Yale durante los meses de septiembre, noviembre y diciembre de 1952, donde colaboraban treinta y dos arquitectos, treinta pintores, dos profesores adjuntos y un crítico invitado -él mismo-, en la primera parte del artículo "The Card-board House"1 publicado en la revista Perspecta. Aparte, es un estudio introspectivo donde el autor considera, a modo de reflexión, que el acto de pensar es una función del individuo y que todo clamor encaminado hacia un grupo homogéneo de pensamiento queda reducido a un falso rumor. Aún así, la trama descubre una lección aprendida que, en palabras de Fuller, intensifica cómo son de importantes los libres deseos de los individuos, que desviados espontáneamente hacia una mutua coordinación, avanzan, en este sentido, para resolver científicamente las incógnitas. La segunda parte del artículo es una reflexión a mayor escala que Fuller utiliza para describir el modelo realizado por siete estu-

${ }^{1}$ Fuller, Buckminster. «The Cardboard House». En: Perspecta, No2, Pensilvania, 1953. También en «R.B.F.» de Daniele Baroni y Antonio D'Avvia. En: Ottogono Nº66, septiembre 1988, año 17, grupo IV, Milano 
diantes de doctorado -Fuller Study Group (FSC) - que se encargaron de continuar el fallido trabajo de colaboración anterior: la producción industrializada de una vivienda que se analiza como si se tratase de un inventariado de preguntas sobre el comportamiento físico del universo. El resultado es una cúpula fabricada a través del ensamblaje de unidades triangulares mediante diversos materiales y de varias instalaciones, como indican las especificaciones técnicas.

Sobre los sistemas de control del medioambiente, en un artículo posterior publicado en la revista Zodiac de 1969, se analiza el carácter global del pensamiento de Fuller que no sólo postula por la validez de una ciencia del proyecto que tiene como aplicación la totalidad de la tierra, sino por unas leyes de pensamiento que son las mismas que gobiernan la estructura del universo, situando al hombre entre los micro-fenómenos y los macro-fenómenos, entre la mecánica cuántica y la teoría de la relatividad general ${ }^{2}$. Establece la equivalencia entre el pensamiento científico y el salvaje al considerar que éste último constituye una inversión de la forma de pensar culta occidental y encuentra las reflexiones de Fuller cercanas a la antropología estructural de Lévi-Strauss y a otras tendencias del estructuralismo francés: J. Lacan, M.Foucault, L.Althusser, etc. Habla de la revalorización de la forma de conocimiento salvaje que incide, una vez más, sobre la concepción sistemática que asume como universales los mecanismos cognoscitivos de la mente humana y la capacidad de ver o de leer lo que se esconde tras la opacidad del dato sensorial, tras el secreto o el lado mudo del ser.

Respecto al sistema sinergético opta por sustituir el aire por el agua, Buckmister Fuller estudia las aguas del sudeste asiático en ciudades como Bangkok, que tiene una red de canales muy desarrollada donde viven gran cantidad de personas que se sumergen, se bañan y lavan sus ropas y enseres en estas aguas turbias ${ }^{3}$. En un libro recopilatorio de la obra de Fuller, John Mc-Hale ${ }^{4}$ comenta la influencia de los estudios de balística y de navegación -los inicios de la mecánica de los fluidos- en la formación de Fuller, al ser la geometría, en esos estudios, una herramienta de trabajo que les sirve para prever y medir las inesperadas fuerzas de la naturaleza, calculando de antemano los sucesos energéticos en el tiempo. Puede que no sea únicamente una previsión, sino una forma de valorar el accidente científico incapaz de controlar las variables de la naturaleza o, tal vez, un aprecio de esa valoración y al igual que sucede con los signos, estos estudios no son absolutos cálculos sobre el mundo real, sino modelos reales excéntricos o alternativos a él.

\subsection{El modelo de fuerzas interiores y exteriores}

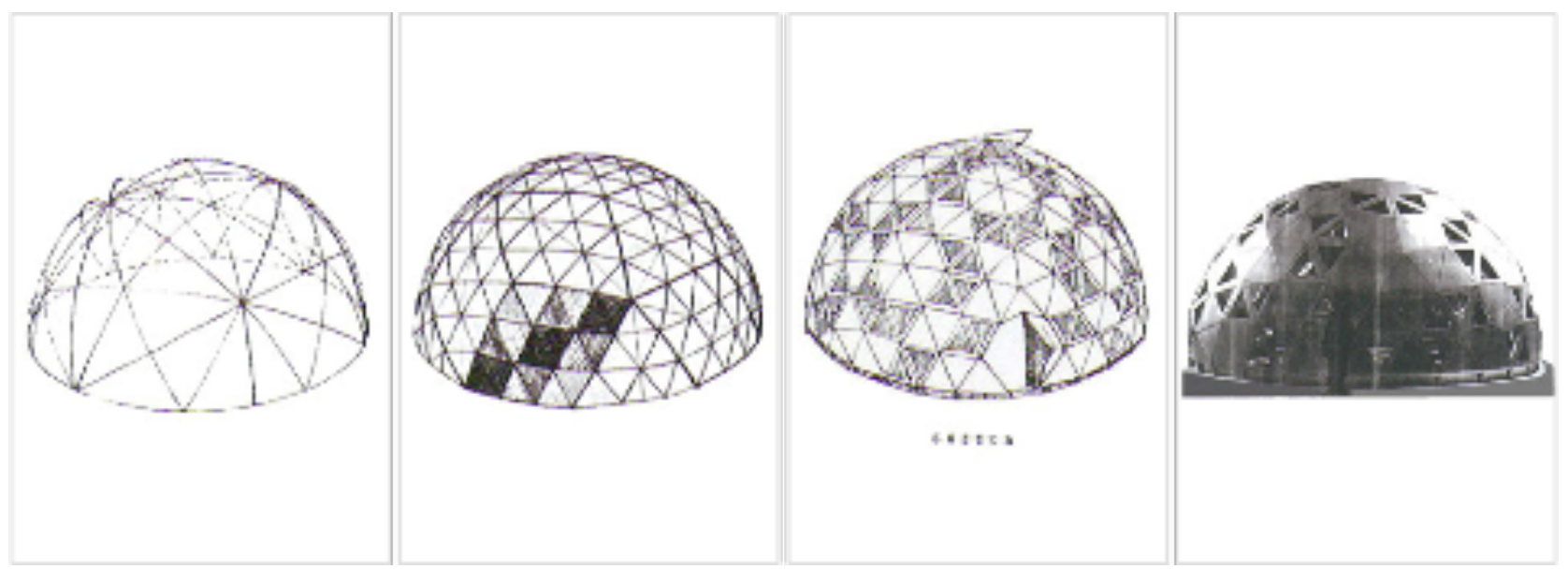

Figura 2. Cúpulas geodésicas 1-4 (modelos). R. B. Fuller, «The Card-board House», Perspecta, 1953

Diferentes fuerzas inciden sobre todo cuerpo cualquiera que sea su situación, unas de origen interno y otras de solicitación exterior. Las fuerzas intermoleculares, variables con la temperatura, determinan el estado sólido, líquido o gaseoso de la materia y son las que originan la cohesión e indeformabilidad en los cuerpos sólidos que mantienen su forma frente a los agentes exteriores. La solicitación exterior permanente es la fuerza de atracción que la tierra ejerce sobre la masa del cuerpo, según Newton. Mientras esta fuerza exte-

\footnotetext{
${ }^{2}$ Una suerte de vista miope o estrábica, como comentaba Fuller: «...Yo nací estrábico. Tenía cuatro años cuando descubrieron que se debía a una anormal visión de lo lejano. Desde entonces mi vista fue corregida con lentes. Hasta los cuatro años solamente pude ver vastas configuraciones, casas, árboles, perfiles de gente con colores desenfocados. Veía sólo dos zonas oscuras sobre los rostros. $Y$ no pude por ello ver ojos humanos o lágrimas o cabellos hasta que no tuve cuatro años. A pesar de la nueva capacidad adquirida para conocer los detalles mi espontaneidad y mi predisposición de la infancia por las grandes configuraciones han prevalecido». Bottero, María. «Abstracción científica y pensamiento concreto en la utopía de Buckminster Fuller». En: Zodiac, Milan, 1969.

${ }_{3}$ Ito, Toyo. «Tarzanes entre los bosques», 2G, Gustavo Gili, Barcelona, 1998.

${ }^{4}{ }^{4} \mathrm{McH}$ ale, John. R. Buckminster Fuller. Creadores de arqutectura contemporánea. Hermes, Madrid.
} 
rior actúa sobre cada una de sus moléculas intentando disgregarlas, modelando al máximo contra ella la masa del cuerpo; las fuerzas intermoleculares se oponen al peso individual de cada particular evitando la disgregación del conjunto, manteniendo su forma. Por ello, repercuten de molécula a molécula y producen tensiones en todo el cuerpo, dependiendo su distribución de la forma, tamaño y puntos de apoyo del cuerpo. Estas tensiones serán en unos puntos de acercamiento o presión -energías de empuje-, en otros de distanciamiento o separación -energías de arrastre- y en algunos de deslizamiento o cortadura. Complementariamente, en un mismo punto habrá efectos de la presión en una determinada dirección y también de alejamiento y cortadura respecto de otros puntos que le son contiguos en otras direcciones. De esta manera, en cada punto surgen unas direcciones efectivas en las que se producen tensiones de compresión, de tracción y de cortadura. Las tangentes de estas trayectorias determinarán en cada punto la dirección principal de esfuerzo, la línea de fuerza o vector. $Y$ en estas trayectorias las tensiones son del mismo signo, pero de intensidades o de grados de energía diferentes. Si en el sistema de fuerzas internas sólo se considera la gravedad, la intensidad del campo es proporcional a la densidad del material como la relación entre la masa y el volumen, reduciendo el problema a dos variables en los cuerpos estáticos: la forma y el material. Por ejemplo, en el caso del acero y las aleaciones ligeras se produce la liberación de la forma debido a la gran resistencia a todo tipo de esfuerzos, principalmente a tracción.

De este modo, las estructuras reticulares permiten cambiar la forma sin aumentar las secciones efectivas de trabajo. Un primer método de diseño dirige los esfuerzos exteriores hasta los apoyos sin que exista una forma propia inicial, ésta se construirá por equilibrio sucesivo de puntos en el espacio siguiendo las líneas funiculares determinadas en un estudio de las propiedades de las figuras en una superficie elástica o comprimida con independencia de su forma o de su tamaño que son equivalentes en topología. Otro método de diseño determina una especie de canalización frente a la inmensidad del océano, pues la estructura reticular no sólo reduce la masa general y separa los esfuerzos de tracción, compresión y cortadura sino también puede conducir estos esfuerzos por canales en una forma previamente determinada. Este último método no se arriesga a las acciones del viento. Tras el despliegue de una estructura reticular, se colocan los elementos de cubierta que pueden ser de materiales textiles o de chapas rígidas; o bien, se diseña una cubierta que acompañe al resto de la estructura en su proceso. En el caso de las cúpulas de dos capas tienen especial interés las que incorporan las planchas como una capa resistente, donde la colaboración es importante porque las estructuras reticulares tienen flechas elevadas y, de este modo, consiguen reducirlas. Los elementos de cubierta esparcen y desvanecen las partes que forman por aglomeración un cuerpo, disipan la causa capaz de transformarse en trabajo mecánico ${ }^{5}$.

Paralelamente, aparecen por una parte unas estructuras de cubierta tan esbeltas que el peso propio es del mismo orden de magnitud que las cargas accidentales, porque aunque intervenga el efecto de las cargas vivas sigue dependiendo del peso como factor predominante dentro de la estabilidad del conjunto; es el caso de los cascarones de hormigón armado. Mientras otras estructuras como las cubiertas de tela y cables de Frei Otto ${ }^{6}$ están constituidas por láminas de peso propio mínimo y la rigidez intrínseca del material es prácticamente insignificante. El viento es la mano que las modela, la fuerza que las mantiene en continuo movimiento con sus acciones imprevisibles y caprichosas y por ello son necesarios varios puntos de anclaje a tierra. Es por esta causa que las condiciones de borde son en realidad determinantes para conseguir con materiales flexibles formas resistentes bajo la acción de las solicitaciones. Esto también implica que el cálculo de los esfuerzos internos es secundario. Se aplica a la superficie una doble curvatura inversa que persigue formas hiperbólicas que no tienen una definición geométrica precisa ni pueden ser expresadas mediante una ecuación simple. La determinación de la magnitud o el valor del módulo de las fuerzas que actúan en los cables más cargados y de los esfuerzos en los puntos más críticos ayudan, pero lo que determina es la definición de la configuración final a través del despiece de la superficie en pedazos de tela que se acoplan perfectamente sin producir arrugas en el caso de una membrana, o bien mediante el cálculo de la longitud final del cable si se trata de una red. Son una clara representación del juego de fuerzas que las mantiene en equilibrio. En relación con los esfuerzos tangenciales, éstos son absorbidos y anulados en los bordes, pues al igual que sucede con los fluidos no pueden ser contrarrestados, ya que surge un continuo e irrevocable cambio de posición de una parte del material respecto a la otra, lo cual constituye un flujo ${ }^{7}$.

\footnotetext{
${ }^{5}$ Candela, Félix; Pérez Piñero, Emilio; Calatrava, Santiago; Escrig, Félix; Pérez Valcárcel, Juan. Arquitectura transformable. Textos de Arquitectura. Publicación de la Escuela Técnica Superior de Arquitectura de Sevilla, 1993.

${ }^{6}$ Otto, Frei. Cubiertas colgantes. Versión española por Francisco Folguera. Editorial Labor, S.A., Barcelona, 1968

${ }^{7}$ White, Frank M. Mecánica de fluidos. McGraw-Hill, Madrid, Año. Traducción de Manuel Rodriguez Fernández, Rodrigo Martinez ValPeñalosa y Amable Liñán Martinez.
} 


\subsection{El modelo de intercambio sinergético}

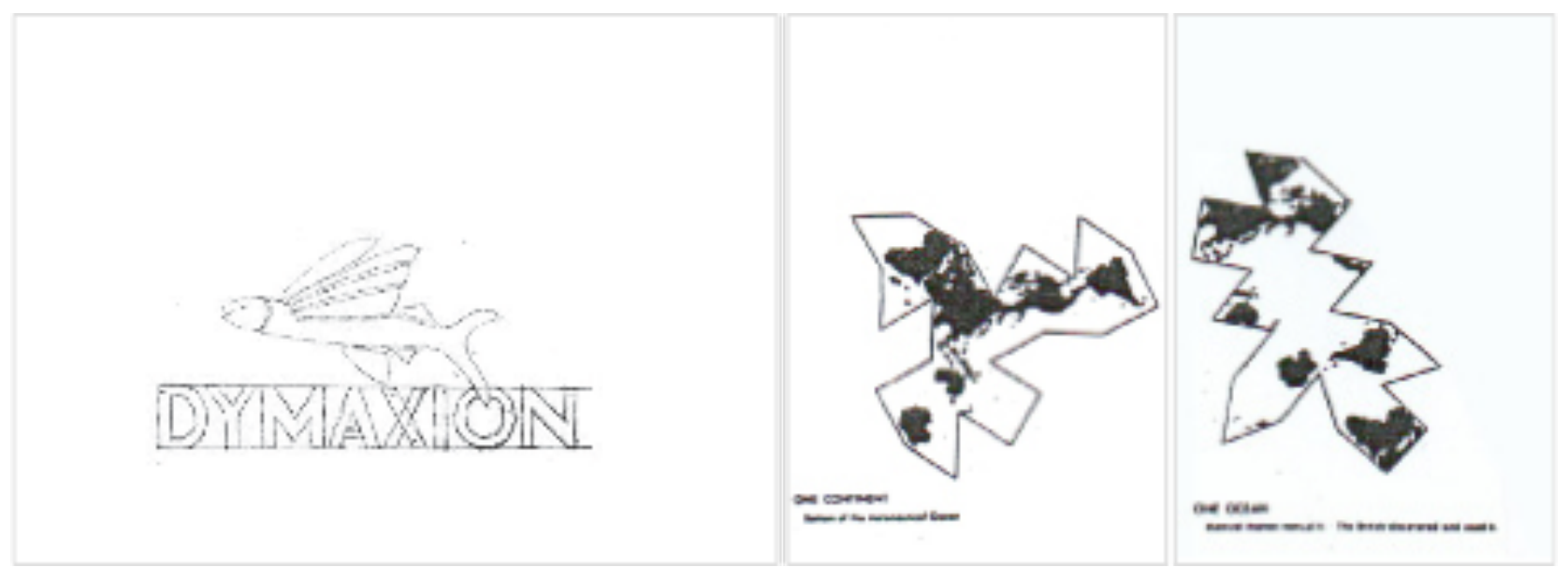

Figura 3. Un pez-volador. Un único continente. Un único océano (diagramas). R. B. Fuller, Dymaxion Map, 1954

Según Buckminster Fuller, la colaboración entre disciplinas científicas independientes, como cuestión que envuelve al cálculo matemático, está concentrada en el desarrollo de la energía y sinergia de la geometría. Traducida a términos biológicos, la sinergía está fundada en las exaltaciones recíprocas del poder patógeno de dos bacterias parásitas que viven en el mismo lugar. Como centro que irradia energía, la mejor geometría platónica o figura atemporal que podría formarse empleando sólo la regla y el compás sería la esfera; sin embargo, la geometría de la cúpula geodésica no es exacta, es una forma de aproximación; es decir, proporciona un límite superior y otro inferior entre los cuales se halla la respuesta y además precisa un movimiento mecánico. Se acerca en su génesis, bien a los poliedros casi irregulares o figuras tridimensionales convexas: bien a los poliedros de Arquímedes, cuyas caras se componen de dos o más tipos de polígonos regulares e idénticos en sus vértices; bien a los elipsoides en función del factor de expansión que aplana la superficie esférica, también presentes en otro tratado "De los conoide y esferoides", donde el físico, matemático y astrónomo griego define las cuatro secciones cónicas: el círculo, la elipse, la parábola y la hipérbo$1 a^{8}$.

Algunas representaciones primitivas muestran árboles cargados de peces entre las hojas, un ejemplo de la magnífica influencia de la metamorfosis en la fabulación animal. Al igual que anteriormente, es más cercano todavía si consideramos el aire como un conjunto de corpúsculos blandos con cierta facilidad para la compresión que dejan, por tanto, pocos intersticios entre ellas; mientras el agua pertenece a otra modalidad de corpúsculos, duros como pequeñas bolas de acero con gran incapacidad a la compresión, los cuales únicamente consiguen deslizarse al no poder absorber los esfuerzos tangenciales. Parecen similares pero el intercambio energético varía de un medio a otro. Dymaxion ${ }^{9}$, esta palabra escrita con línea de puntos y letra hueca, subrayada arriba y abajo por Fuller, es un límite entre el cielo y el océano, un horizonte marítimo, y tiene justo encima un ser que se debate entre esos dos mundos: el pez volador o una cola de pez provista de alas. Es un ser de vida marina que provoca contaminaciones entre el pájaro y el pez, mediante composiciones casi geométricas del vuelo y de la natación, como Leonardo da Vinci escribe en su cuaderno de notas. Bachelard acepta una homotecia mecánica: el pájaro y el pez viven en un mismo volumen, mientras el ser humano vive en una superficie, y como el pájaro y el pez tienen un comportamiento dinámico semejante, aire y agua, no es absurdo confundir los dos géneros animales en el reino de las impulsiones de la mecánica, de la imaginación motriz ${ }^{10}$.

En el texto publicado en Yale expone una filosofía y una estrategia fundadas en la sinergia que define como el comportamiento de los sistemas, los complejos y los modelos más entreverados que lo que hace suponer la simple suma de sus partes, sin poder prever de antemano el resultado formal mediante algunos gestos particulares. Es un contrapeso al adjetivo "energético" que afecta a partes aisladas de un sistema, funcionando individual o localmente. La retícula interior de la cúpula geodésica es el resultado de la colaboración de las partes que la componen, sin necesidad de diferenciar entre las partes sustentantes o sustentadas, las

\footnotetext{
${ }^{8}$ Torija Herrera, R. Arquímedes. Alrededor del círculo. Colección «La matemática en sus personajes». Nivola libros y ediciones, S.L., 1999.

${ }^{9}$ Fuller, Buckminster. The Artifacts of R.B.F. Volume four: The Geodesic Revolution part 2. 1960-1983. Editado por James Ward con un apéndice firmado por D. L. Richter. Garland Publishing, Inc. New York and London, 1985.

${ }^{10}$ Bachelard, Gaston. El agua y los sueños. Fondo de Cultura Económica, Madrid, 1994.
} 
principales o las secundarias, consiguiendo el máximo espacio cubierto con el menor gasto de energía. El aire puede ceder o adquirir calor en función de la capacidad de absorción de la superficie, y de este modo mientras una molécula de aire cede calor, su volumen se reduce al cubo y su superficie disminuye al cuadrado, cediendo calor más rápidamente cuanto más pequeña es de tamaño. Multitud de moléculas de aire en retícula forman esas cúpulas geodésicas, donde continente y contenido parecen indiferenciados. En esta cualidad sinergética del medio - no sólo de la geometría-, el aire se confunde con el agua, dado que la superficie para cualquier fluido en reposo es la de una esfera cuyo centro es el mismo que el de la Tierra.

\subsection{El modelo de matrices vectoriales}
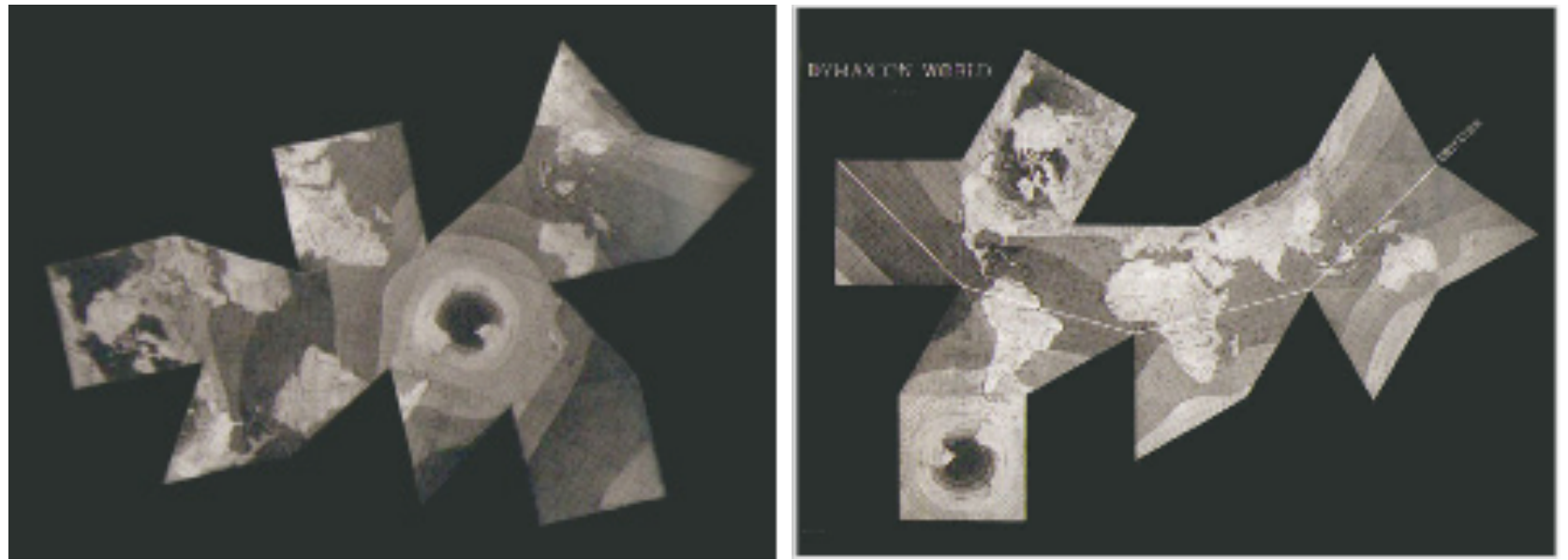

Figura 4. Cartografía 1-2 (mapas). B. Fuller, Dymaxion Map, 1954

Fuller busca una disposición mínima de vectores o de líneas de fuerza para manejar el sistema energético de un modo comprensible y emplea, para ello, una geometría de catorce facetas a través de una apretada agrupación de esferas alrededor de un núcleo central. La distancia entre el centro del poliedro de lados de igual longitud y cada uno de los vértices recibe el nombre de vector equilibrio. Este vector forma uniones que oscilan entre la simetría del equilibrio y varias asimetrías entre los grupos de esferas, de manera que cada esfera es un campo de energía al cual tienden todas aquellas fuerzas que están coordinadas en patrones asimétricos positivos y negativos. En conjunto forman un vector matriz isotrópico, es decir, un sistema en el que todos los vectores tienen la misma longitud y todos los vértices son equidistantes, determinando una topología omnidireccional que proporciona un sistema dinámico de coordenadas y se ajusta a las exigencias de las leyes físicas. Esta forma compleja se subdivide en tetraedros, siendo éstos el sistema de energía de dimensiones mínimas o la configuración vectorial más reducida. Existe un sistema vectorial de referencia en equilibrio dinámico que sirve para medir la conversión de cualquier grado de desequilibrio en un factor de energía de desarrollo previsible.

A través de diferentes modelos que sirven de generalización, en vez de representaciones que sólo pueden reflejar un caso especial, Fuller considera que la forma tiene unas dimensiones mientras que el modelo es independiente del tamaño. De modo que un triángulo identifica la energía con los números dando lugar a una geometría "energética" que emplea ángulos de $60^{\circ}$ para conseguir cerrar el volumen de la esfera. Vectores y tensiones constituyen todas las definiciones. Las matemáticas envueltas en el proceso sinergético unen la topología con la geometría vectorial, al ser la topología la parte de las matemáticas que trata de la continuidad y las propiedades de las figuras con independencia de su tamaño o forma y la geometría, otra parte de las matemáticas que habla de las propiedades y medida de la extensión. Maneja integrales (no derivadas), agrega, formando sistemas completos impredecibles por los ensamblajes de cada una de sus partes y toma una a una por separado. Para Buckminster Fuller una matriz de vectores isotópicos proporciona una forma de conocimiento, un modelo más flexible que el esquema de tres ejes $X Y Z$, al definir física y matemáticamente el modelo como una matriz orgánica alejada del cubo y próxima a las esferas, las burbujas y los átomos. A propósito de la matriz, ésta llega a configurarse como un conjunto de números o símbolos algebraicos colocados en líneas horizontales y verticales que se disponen en forma de rectángulo, como una víscera hueca o como un molde de cualquier clase.

\subsection{El modelo de los poliedros energéticos}



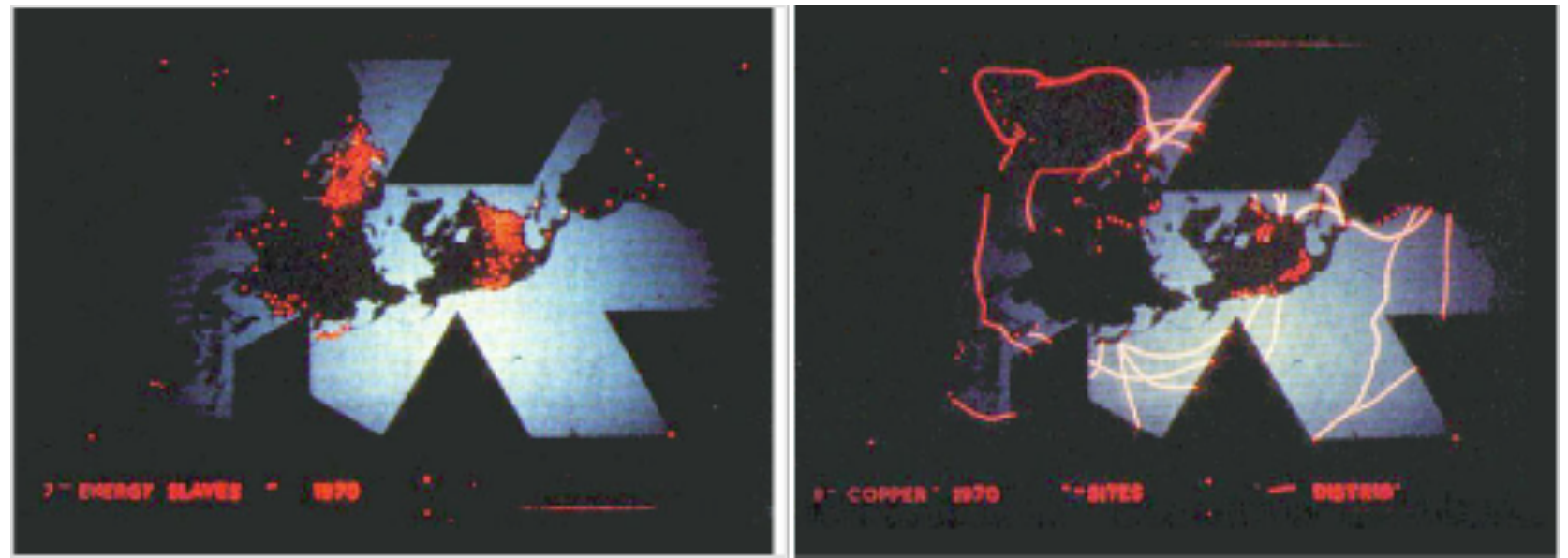

Figura 5. Distribución de energía 1-2 (pantallas). B. Fuller, Dymaxion Map, 1954

Dentro de los estudios geométricos de Fuller, el tetraedro es una figura que responde claramente a un sistema estructural básico y que consigue transformarse en varias figuras a través de las fases cero. Primero en sentido decreciente: un triángulo es un tetraedro de altitud fase cero, una línea es un tetraedro de base fase cero y un punto es un tetraedro de fase cero combinada con altura y base. Después en sentido creciente: una esfera será un poliedro formado por una invisible pluralidad de facetas triangulares. El tetraedro regular limita el mínimo volumen con la mayor superficie de todos los poliedros geométricos; mientras que la esfera encierra el mayor volumen con una menor superficie; además, la estructura mínima que define una esfera es un tetraedro regular de seis grandes arcos de círculo máximo con ángulos centrales de $109^{\circ} 28^{\prime}$ y ángulos superficiales de $120^{\circ}$. Esas figuras rellenas y compactas formadas por tejidos que dan lugar a estructuras huecas son las retículas espaciales tetraédricas, las cuales se unen mediante envolventes que parecen invisibles a primera vista para el ojo humano. Existen en las transformaciones geométricas unas propiedades de las superficies que permanecen invariables. Si se efectúa una partición de una superficie esférica en triángulos esféricos, se observa que la suma $X=C-L+V-2$ (número de Euler), donde $C$ es el número de triángulos, $\mathrm{L}$ el de lados y $\mathrm{V}$ el de vértices, no depende de la triangulación realizada y es igual a cero. De este modo, $\mathrm{X}$ vale también cero para todos los cuerpos geométricos equivalentes a la esfera.

Quizá el método de Fuller, que toma como referencia el océano del aire para llegar a elementos mínimos, tetraedros, que después se pueden ampliar o agrupar en unidades superiores, esferas y favorecer sus características térmicas, es un proceso aditivo. Es diferente de algunos principios que basándose en el contraste energía-sinergia, individualizan la línea de fuerza que afecta a la complejidad del sistema universal, hasta descomponer dicha esfera, dichas líneas en elementos celulares como octaedros y tetraedros, de forma que el tetraedro resulta ser el mínimo sistema energético dimensional. $Y$ aunque todo tenga que hacerse empíricamente ya que el concepto de sinergia afirma que el comportamiento de los totales complejos, sistemas, patrones- es impredecible por medio del comportamiento de una de sus partes, son precisas las interacciones. Dicha estrategia sinergética parte de las mayores experiencias, de los principios más generales hasta llegar a evaluaciones secundarias que deben ser complementadas funcionalmente con el concepto original y todo ello está centrado en la presencia de la conciencia humana y su objetiva participación en el funcionamiento de un patrón global, es decir, de la Tierra en el Universo.

\subsection{El modelo de ensamblaje tridimensional}

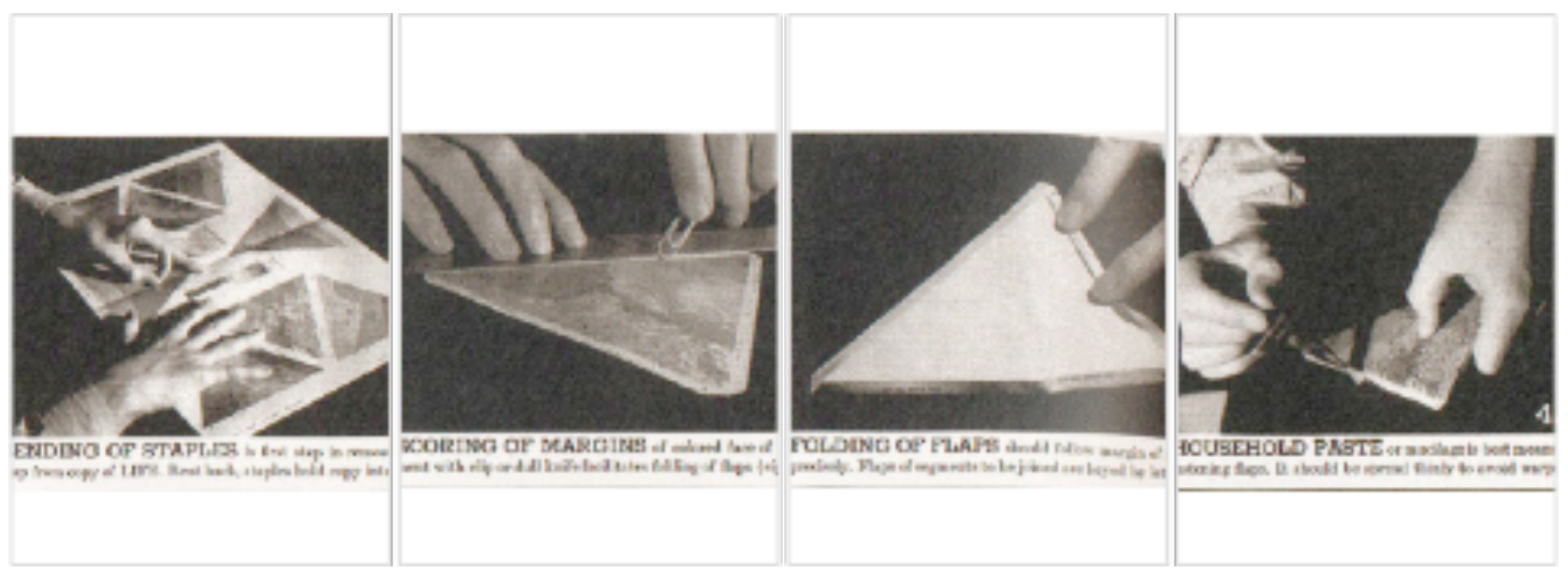


Figura 6. Dymaxion Map. Doblar los bordes (maquetas). R. B. Fuller, Dymaxion Map, 1954

El ensamblaje de los modelos utiliza los métodos de abordo, es decir, los instrumentos que se encuentran a disposición alrededor de él, y avanza por tanteos. La operación deriva del plegado de las unidades triangulares, de forma que dos personas puedan montar una cúpula en un día. Siguiendo a Lévi-Strauss, el proceso de ensamblaje abandona toda referencia a un centro, a un sujeto, a una referencia privilegiada o a un origen y esas ausencias son las que motivan los movimientos de los elementos suplementarios. El bricoleur es aquella persona que obra sin plan previo y con medios y procedimientos apartados de los usos tecnológicos comunes, es decir, no opera con materias primas sino con productos ya elaborados, con fragmentos de obras, con sobras y trozos. Es capaz de ejecutar un buen número de tareas pero, al contrario que el ingeniero, no subordina ninguna de ellas a la obtención de materias primas y de instrumentos concebidos y obtenidos a la manera de su proyecto: afirma que su universo está cerrado y la regla de su juego es siempre la de arreglárselas con lo que uno tenga a mano. Los medios de un bricoleur no se pueden determinar por un proyecto, se definen solamente por su instrumentalidad; o bien, porque los elementos se recogen o conservan porque se intuye algo para lo cual habrán de servir; son operadores ${ }^{11}$.

\subsection{El modelo de procesamiento de datos}

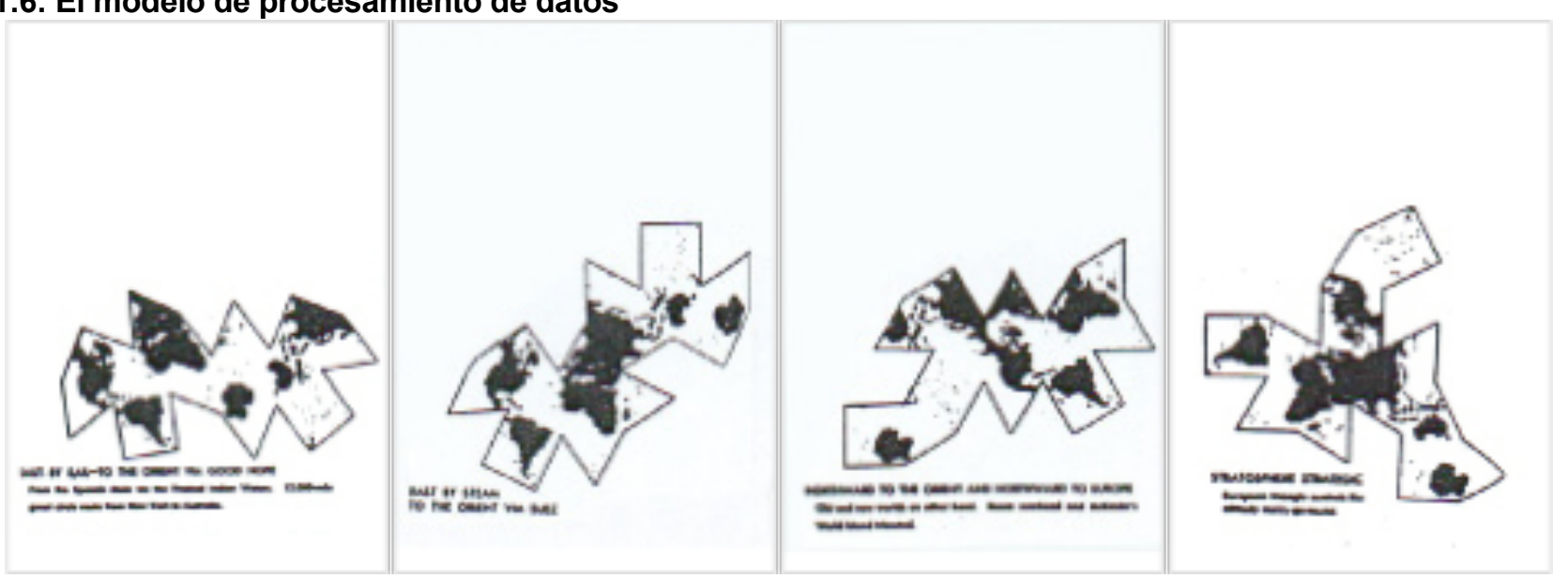

Figura 7. Estrategia estratosférica (diagramas). R. B. Fuller, Dymaxion Map, 1954

Los modelos dejan de ser objetos para convertirse en procesos infinitos que toman en consideración el conjunto de fuerzas que los producen y los transforman, en toda su diversidad. El modelo Tensegrite, donde coexisten una tensión continua de los cables y una compresión discontinua de las varillas, alcanza su mayor interés en la presencia casi invisible, casi irrepresentable del hilo que vincula una barra con otra, independiente de la reunión final de la forma. De este modo, Fuller al plantear las relaciones de la arquitectura con el medio físico en términos de energía separa las fuerzas de compresión en elementos relativamente cortos y de tensión en cables largos y varillas y llega a las estructuras Tensegrity (Tensional Integrity), que se aplican principalmente en las redes esféricas triangulares de las cúpulas geodésicas.

Del mismo modo, los modelos de la serie repetitiva del World Map muestra disposiciones giradas del esferoide terrestre, según sea la información que se quiere mostrar: un continente o un océano; siempre masas observadas a larga distancia. Este atlas en miniatura posee un tamaño tan pequeño que pierde la función de mostrar los continentes sobre una superficie plana sin una distorsión visible. Mediante el uso de miniaturas, el modelo se libera de su significado oficial para convertirse en objeto portátil, que trata de mostrar algunos movimientos inapreciables para el ojo humano por su invisibilidad o por su lentitud; por ello, es un código indicativo -multitud de flechas van en grupo de un lado para otro- de las fuerzas que actúan sobre la Tierra. El hombre reconoce una escala de movimientos muy limitada dentro del espectro y la mayoría de las tendencias y de los acontecimientos son invisibles, unas sacudidas inexorables lo asaltan por sorpresa mientras unos hechos históricos demasiado lentos para su ojo y su mente le despiertan apatía. Desde el océano de aire donde el ser humano se mueve en materia de transportes, canalizado en líneas que marchan en direcciones opuestas y se extienden entre árboles y edificios con un desplazamiento muy lento por la congestión, Fuller propone ascender y salir de la superficie, para poder utilizar todas direcciones del espacio aéreo. Únicamente una aproximación y una configuración que actúa por tanteos pueden solucionar las complejidades físicas. Así nace la ficha técnica procedente de los prototipos industriales y de las técnicas de

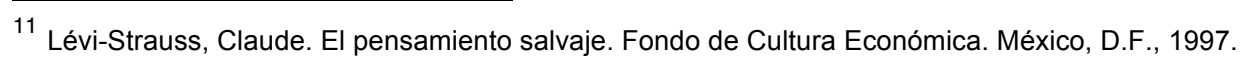


reproducción en serie, cuyo modelo de la cúpula geodésica fue patentado y protegido por el grupo Fuller Research Foundation.

\section{Los modelos energéticos de R. Le Ricolais ${ }^{12}$}

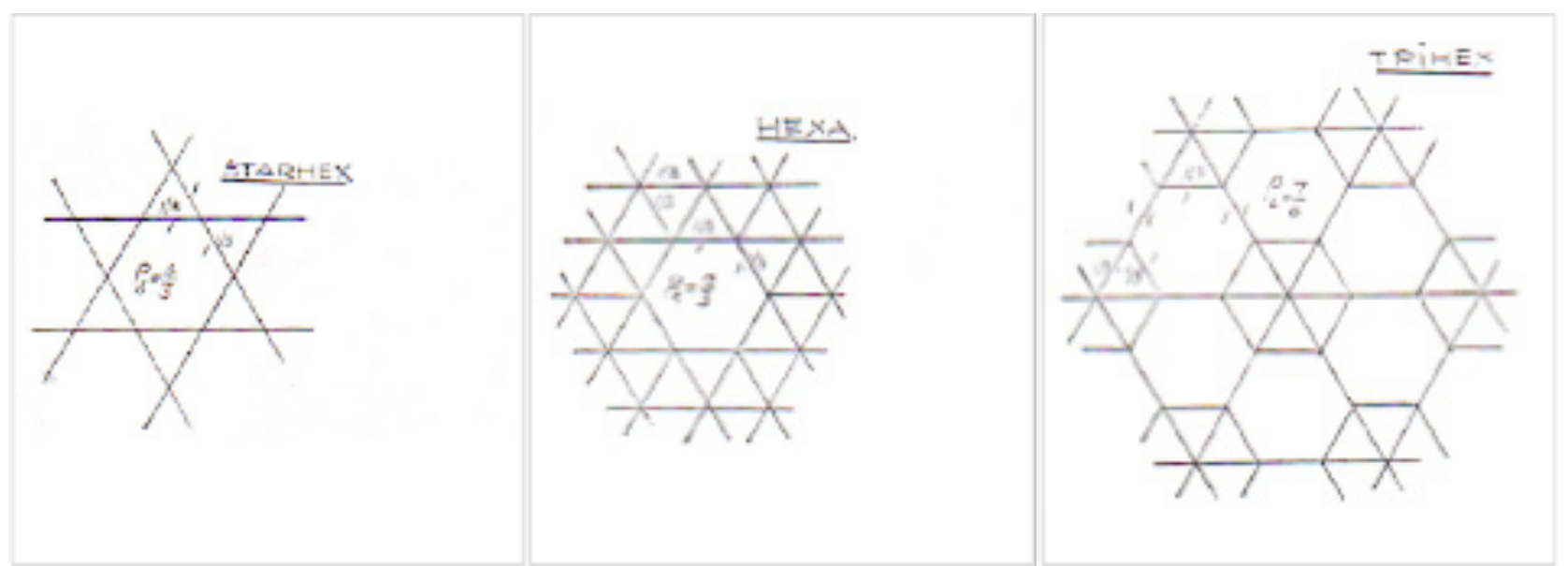

Figura 8. Malla tetraedrica Configuración del espacio definida por la relación 4/3, 2/3 y 7/6 (ejes). R. Le Ricolais, Starhex, Hexa, Trihex. 1962-68

A partir de 1935, Robert Le Ricolais comienza sus estudios sobre los sistemas circulatorios investigando temas aparentemente alejados de su campo de aplicación. Cita a varios autores a propósito del encuentro que se produce entre los cristales salinos -Homogeneus Division of Space (1887) de Lord Kevin- y los radiolarios orgánicos- Principes of Morphologie Générale (1866) de M.E.Monod Herzen-, ambos vinculados al mundo submarino ${ }^{13}$. También nombra al biólogo alemán Ernst Haeckel, quien realiza un Atlas con las ilustraciones de la expedición Challenger Reports (1878) y describe detalladamente unos seres sin gravedad, los radiolarios: "Callimitra" tetraédrica con arcos perimetrales tridimensionales, "Tridictyopus" ovoidal con arcos de refuerzo, "Actininomma» o "Pytyoma» de arborescencia radial como flechas clavadas en la superficie y "Otosphaera" de arborescencia plena con ramificaciones nerviosas dispuestas en bloque ${ }^{14}$. En su mayoría están compuestos por una doble retícula interior de trazado semi-regular de hexágonos y triángulos yuxtapuestos con unas espinas radiales que surgen del centro de dichos hexágonos y por una membrana exterior o velo de doble curvatura que recoge directamente la presión hidrostática del medio fluido, la cual trabaja a tracción y dispersa los apoyos por toda la superficie de la esfera con el fin de evitar un esfuerzo localizado. Como la cúpula geodésica, la esfera presenta en la superficie el mayor número posible de triángulos, porque, bajo la presión hidrostática, la curvatura de la esfera aumenta y cada elemento de ella debe asumir las compresiones, siendo preciso tener una malla equilátera que reparta equitativamente y una superficie máxima para una longitud y una sección determinadas.

Son poliedros de gran complejidad que quedan reducidos a sus aristas y ponen en contigüidad estructuras de diferentes tipos en pequeños organismos marinos, cuya embrionaria es comparada con la de los organismos superiores. Su concentración forma barros de radiolarios que determinan los sedimentos oceánicos y constituyen las rocas sedimentarias silíceas denominadas radiolitas. Estos seres de disposición trirrectangular flotan en masa junto con otros elementos del plancton, gracias a su constitución perfectamente adaptada a la suspensión dentro del medio líquido. ¿Son ellos, quizás, los vastos prados de «brit», cuya sustancia diminuta y amarilla constituye el alimento principal de la ballena común? Dicho plancton lo forman seres vivos cuyos movimientos pasivos verticales predominan sobre los activos horizontales; flotan a un determinado nivel, ya sea con ayuda de flotadores cerrados llenos de aire o de aceite que disminuyen su densidad, ya sea con la ayuda de vastas extensiones que hacen a la vez el papel de paracaídas y de remo. ¿Cómo sería el sistema estructural de otro conjunto de seres que nadan y migran estacionalmente buscando las condiciones más adecuadas -cefalópodos, peces y cetáceos- y forman el necton? ¿Y la de aquellos seres que viven fijos en el fondo marino, se desplazan poco -algas fijas, corales, esponjas, crustáceos y algunos

\footnotetext{
${ }^{12}$ Le Ricolais, Robert. «Under Sea Transit». En: Architectural Design, 1970.

${ }^{13}$ Mimram, Marc. Structures et formes. Étude appliqueé à l'ouvre de Robert Le Ricolais. Préface Paul Chemetov. Dunod: Presses Ponts et Chaussèes, Paris, 1983.

${ }^{14}$ Le Ricolais, Robert. «Considerations sur la geometrie des radiolaires». En: Zodiac22, en AAVV: Light structures, Milan, 1973. Forma parte del texto enviado a «The International Conference on Space Structures», University of Surrey, September 1966, y publicado en el volumen «Space Structures», editado por R.M. Davies, Blackwell Scientific Publications, Oxford y Edimburgo, 1967.
} 
peces como lenguados y rayas- y definen, en conjunto, el bentos como palabra derivada de la griega benthos que significa profundidad y el propio Haeckel inventó en oposición a plancton?

Dentro de esta teoría general puede inscribirse la rama denominada «Cetología» que Helman Melville describe con todo lujo de detalles en Moby Dick, dentro de unos límites, como él mismo reconoce, al comentar que no promete nada definitivo, pues cualquier cosa humana que se dé por completa debe resultar por esta misma razón como imperfecta. Continua diciendo que no pretende establecer una minuciosa descripción anatómica de las diferentes especies -no por lo menos aquí-, ningún estudio sistemático sobre cetología, pues se define el arquitecto, pero no el constructor ${ }^{15}$. A continuación, cita el Sistema de la Naturaleza de Linneo, publicado en $1776^{16}$, mostrando su desacuerdo con esta clasificación porque separa las ballenas de los peces a causa del corazón bilocular caliente, sus pulmones, párpados móviles y oídos profundos, argumentando que los restantes peces no tienen pulmones y su sangre es fría, a lo que Melville replica con la definición: «En pocas palabras, la ballena es un pez surtidor con una cola horizontal».

También en sus primeros estudios Le Ricolais relaciona áreas de conocimiento que hasta ese momento se encontraban distanciadas, campos como la biología, la botánica, la geometría, la cristalografía y la topología, delineando un claro equilibrio entre el rigor analítico y el pensamiento analógico. Sus escritos iniciales «Les toles composees» (1935) y «Les structures tridimensionnelles» (1940) ${ }^{17}-$, según Paolo Nepoti, son, de la actividad práctica, su signo, como índice que remite por contigüidad a otro estudio: de la observación de las estructuras orgánicas a la inducción de principios constructivos y de allí a la deducción de las características de un nuevo modo de proyectar estructuras. En el ensayo «A la reserche d'une mechanique des formes» $(1965)^{18}$ analiza el origen de los grafismos simbólicos y de los signos mágicos. Pasa por la mitología griega atribuyendo a Prometeo la concesión del primer eje de referencia del hombre, la verticalidad y el poder del fuego. Nombra a Arquímedes en la conquista definitiva de los elementos del espacio, quien al mismo tiempo anticipa el calculo diferencial. Encierra la palabra Topología entre la continuidad y la contigüidad que se da entre dos puntos que son incidentes en una línea y dos líneas que son incidentes en un punto, manteniendo un diálogo entre los grafismos abiertos -letra $Y-y$ los cerrados -letra $A-$, que otorga la respuesta al geómetra A. Cremona y al físico J. C. Maxwell: el esquema Y representa una configuración de barras, mientras que el esquema A son las fuerzas existentes en esas barras; la condición de equilibrio exige el cierre de A. Le Ricolais escribe que este concepto geométrico proviene de la Estática Gráfica, cuyo método de representación plana de los sistemas espaciales es señalado en 1902 por Benjamin Mayor, siendo preciso dibujarlos en dos dimensiones mediante vectores; esto es, gráficamente, a través de flechas.

\subsection{El modelo estructural de un puente en un medioambiente aéreo}

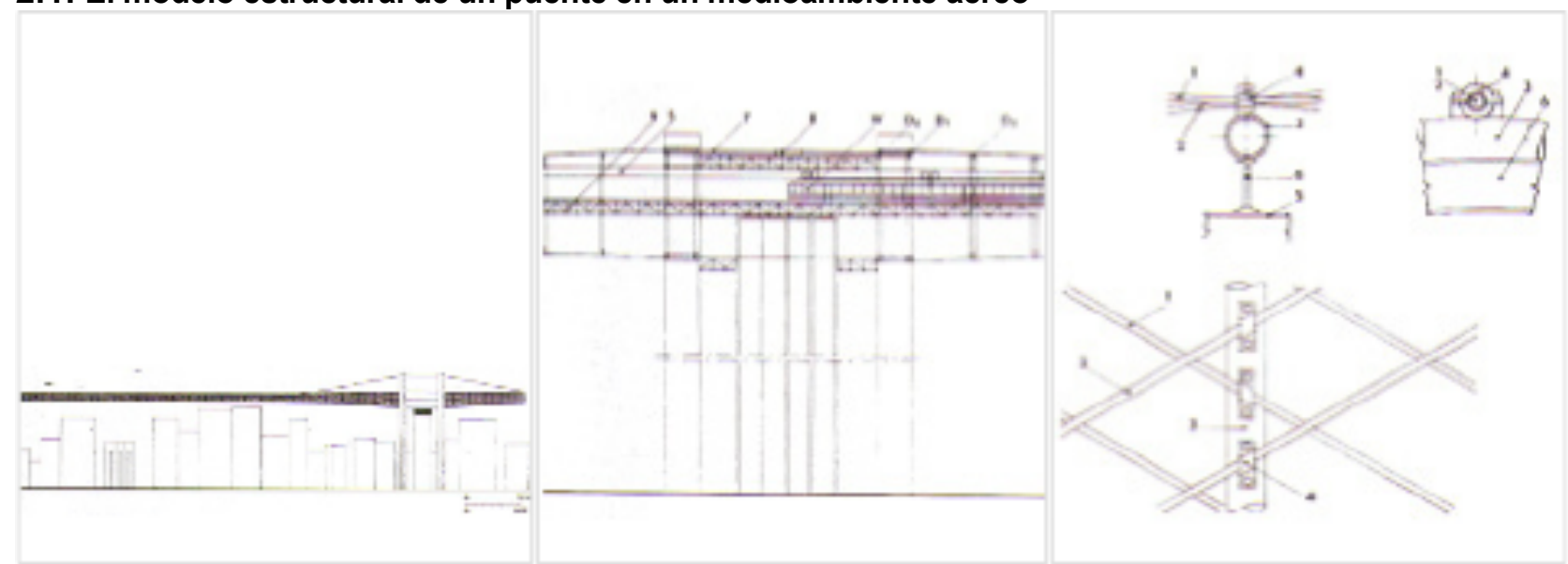

Figura 9. Puente colgante de tubo funicular con estaciones de descenso cada 500 m (aire). R. Le Ricolais, Projet de Sky-Rail, 1970

\footnotetext{
${ }^{15}$ Melville, Herman. Moby Dick o la ballena blanca. Santillana, S.A., Alfaguara, Madrid, 1997.

${ }^{16}$ En 1731, realizó la clasificación binaria de las plantas fundada en los caracteres de los estambres y pistilos, siguiendo un esquema convencional que atribuía a cada especie un doble nombre latino, genérico y específico. Sus publicaciones más importantes son Genera Plantarum (1737), Species plantarum (1753) e Iter Hispanicum y Plantae Surinamenses (1775). Linneo, Carl Von. Naturalista y médico sueco (1707-1778).

17 Nepoti, Paolo. «Premessa a Le Ricolais». En: AAVV: Lights Structures, Zodiac №22, Milan, 1973.

${ }^{18}$ Le Ricolais, Robert. «Á la recherche d'une mécanique des formes». En: AAVV: Lights Structures, Zodiac No22, Milan, 1973. Conferencia dada en el Palais de la Découverte el 7 de julio de 1965.
} 
En un entorno atmosférico, la propuesta «Sky-Rail» (1953), Le Ricolais introduce un medio de transporte que traduce la tecnología del metro y propone un cambio del medio subterráneo por el aéreo, un intercambio de dos elementos: tierra y aire. La referencia al metro no es sólo por el aspecto lineal -posibilidad de unir dos puntos con una línea recta sin necesidad de tener en cuenta lo que sucede debajo (puente) o encima (metro)- sino por la disposición de los elementos para que el engranaje funcione. Las torres de comunicación que bajan hacia la superficie recogen tres niveles de vías dobles y están colocadas a una distancia de 500 metros que es la misma que separa dos estaciones de metro. Calcula que la capacidad de pasajeros por el monorraíl será de 10.000 personas por hora.

En resumen, son cuatro los temas fundamentales que Le Ricolais inserta: las estructuras catenarias tensadas, la partición triangular o hexagonal de los trazados urbanos que forman ángulos de $120^{\circ}$ y facilitan la visibilidad, las áreas de contacto de las torres que se convertirán en grandes vestíbulos de centros de actividad y, finalmente, la intromisión de soluciones utópicas. En el texto que explica el proyecto, el autor ya adelanta su modelo teórico "Trihex» (ángulos para automóviles) y «Tridgrid» (lados para peatones) basado en una partición semi-regular de hexágonos y de triángulos, la cual reduce considerablemente el número de intersecciones con relación a una cuadrilla octogonal de la misma superficie. No obstante, él mismo reconoce que un modelo compuesto únicamente de hexágonos obligaría a una circulación en zigzag, siendo la comunicación rectilínea la más apropiada para el auto. Por ello, la organización de «Trihex» permite también la circulación en línea recta y diferencia las áreas triangulares, privadas (pequeñas), de las hexagonales, públicas (grandes). La distribución del espacio en cuatro direcciones ortogonales-el ángulo continúa siendo imprescindible para la definición de la forma-, se deriva de aquella costumbre de reconocer los fenómenos astronómicos a partir de la salida del sol por el este ${ }^{19}$.

\subsection{El modelo energético de un túnel en un entorno acuático}

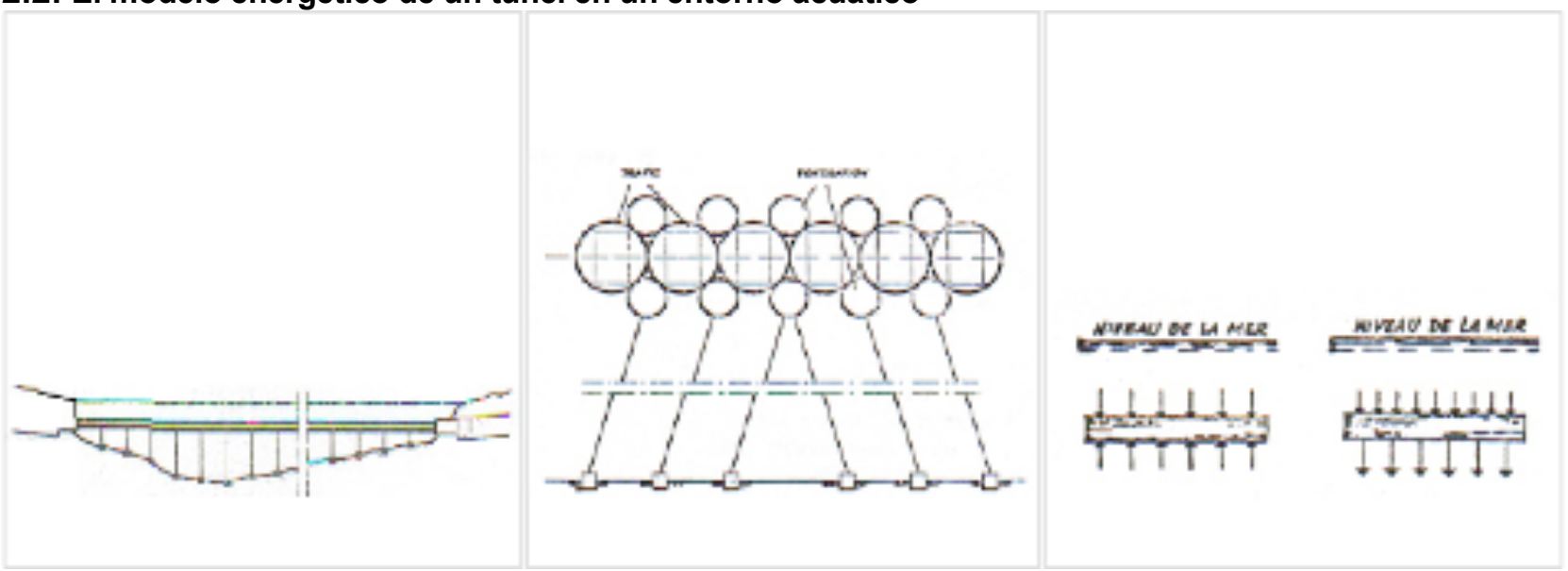

Figura 10. El nivel de flotación está a $35 \mathrm{~m}$. bajo el nivel del mar y da una presión hidrostática de $3-5 \mathrm{~kg} / \mathrm{cm} 2$ (agua). $\mathrm{R}$. Le Ricolais, Under Sea Transit, 1970

Datos técnicos introducidos en el modelo Túnel:

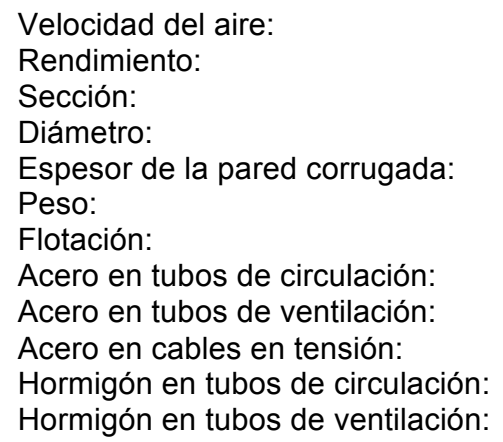

$5 \mathrm{~m} / \mathrm{s}$

$75,50 \mathrm{~m} 3 / \mathrm{sg}$

$15-10 \mathrm{~m} 2$

$4,40 \mathrm{~m}$

$1,70 \mathrm{~cm}$

2,90 ton/m ó $9850 \mathrm{t} / \mathrm{ud}$

15-10 ton hormigón /m

117.000 ton

59.200 ton.

500 ton.

$122.000 \mathrm{~m} 3$

192.000 ó $314.000 \mathrm{~m} 3$.

Dentro de un entorno submarino, el proyecto "Under Sea Transit" de La Ricolais presentado al concurso internacional organizado por la Direzione Generale dell'ANAS para la realización de una carretera y un tren

${ }^{19}$ Le Ricolais, Robert. «The Trihex: New Pattern for Urban Space». En: Progessive Architecture, February 1968. 
permanentes entre Sicilia y el Estrecho de Messina, analiza en primer lugar el trazado de un puente, pero dicha propuesta es rechazada por los movimientos sísmicos y por la profundidad a la cual se encuentra la tierra sumergida. Después, analiza el diseño de un túnel con la condición de evitar los momentos flectores, decidiendo que la flotación quede anclada a tierra para asegurar la dirección de las cargas muertas y vivas de la estructura. El nivel de flotación es empíricamente elegido a una profundidad de 35 metros por debajo del nivel del mar, con una presión hidrostática de $3-5 \mathrm{~kg} / \mathrm{cm} 2$, aproximadamente. Si se asegura un tubo de flotación, la carga muerta de cualquier tipo tendrá que estar inmersa para asegurar una tensión por unidad lineal y mantener la inmersión bajo un nivel. Esto requiere unos cubos de hormigón armado semejantes a los usados en el Puente Golden Gate.

Frente al cálculo de modelos en un sistema aéreo que dan prioridad a la fuerza de la gravedad, aquí fue necesario combatir la flotación y adquirir peso al desconocer las condiciones del nuevo medio. Minimizarla en función del tamaño del tubo que requiere un diámetro muy pequeño $(600 \mathrm{~mm})$, obliga, por tanto, a incrementar el peso propio del tubo de alguna forma artificial; por ejemplo con el uso de cimentaciones de hormigón para soportar las cargas en movimiento dentro del tubo. Sin embargo, es aún insuficiente, y las cargas muertas del hormigón tienen que ser atadas al tubo flotante mediante unos cables en tensión. Se toma la decisión de diseñar un tubo individual en cada vía de tráfico para minimizar la flotación del sistema. Esto también proporciona una gran seguridad y flexibilidad en el manejo del tráfico y exige para salvar los terremotos la adopción de tubos corrugados flexibles, consiguiendo también el tamaño óptimo para soportar la presión hidrostática. Dichas condiciones de presión también han sido tomadas en consideración y se ha adoptado un coeficiente de seguridad igual a 2. Para que puedan actuar conjuntamente los seis tubos de tráfico y los periféricos de ventilación tienen que estar fuertemente atados con cables ${ }^{20}$.

La repetición de un tema estructural relacionado con la energía está ligado al principio de automorfismo-la constitución de una forma sinusoidal que se repite a sí misma de idéntica manera, con una periodicidad cíclica ligada al coeficiente como módulo de inercia-, ha guiado el proyecto "Under Sea Transit". Los tubos "Isoflex", gracias al artificio de las ondas o de las canaladuras, consiguen que la rigidización de la coquilla se mantenga constante y, así, Le Ricolais concibe una estructura cuya resistencia proviene de la ondulación cruzada en ángulo recto de dos tubos, uno dentro de otro, soldados por los puntos de contacto que se producen en las generatrices. Empleando el método topológico de la imagen, existe cierto isomorfismo entre este sistema Isoflex y un cierto tipo de estructuras triangulares -poliedros cuyas caras no son polígonos sino agujeros-, dando lugar en su encuentro a un nuevo sistema que se define como tubo automórfico triangular. El concepto de isotropía, que destaca en la situación simétrica descrita anteriormente, anula uno de los componentes del vector, en este caso, se trata de la dirección, al ser la propiedad que mantiene constantes las cualidades físicas sin hacer referencia a la dirección en la cual están evaluadas, que traducido a ángulos se reduce a buscar la uniformidad en las direcciones perpendiculares. Si se encuentra sumergido, la intrínseca rigidez del tubo en todas las direcciones se encuentra afectada por las fuerzas que surgen de las corrientes submarinas. Como representación de un campo continuo de fuerzas, la experimentación mediante modelos se realiza a través de un obstáculo similar al que será introducido en las corrientes marinas, cuya simulación consiste en usar un tubo de acero corrugado de un determinado diámetro, sujeto a fuerzas verticales escaladas como las fuerzas de flotación y, al mismo tiempo, el comportamiento elástico será observado, medido y comparado con los datos teóricos de un sistema de computación simplificado.

Unos meses después de la publicación de la revista Perspecta n² (1953), Le Ricolais se pone en contacto con Louis Kahn debido al interés que despertaron en él las investigaciones realizadas en un artículo de esa publicación sobre el centro de Filadelfia. La metáfora del agua cobra vida y ahora Le Ricolais tiene que hacer frente a un conjunto de factores aún más incontrolables que los descritos para el proyecto de Filadelfia porque no son canalizaciones sino vastas extensiones de agua las que conforman la nueva atmósfera.

\section{Conclusiones}

En los modelos de Buckmister Fuller, el interés por los comportamientos globales, como se puede observar en los mapas Dymaxion, le conduce a eliminar datos cambiantes y controlar ciertos parámetros medioambientales. Reconoce la arquitectura como un lenguaje, un producto colectivo sobre el que se proyectan formas y estructuras sociales, o bien como una ciencia universal de coordinación de los recursos, una capacidad de hacer preguntas más allá de lo contingente. Fuller trabaja con vectores, incorpora los mecanismos que observa en los factores medioambientales para luego actuar frente a ellos en el interior de un laborato-

${ }^{20}$ Ibid. 12. 
rio -la lluvia, el frío y los insectos son factores negativos-, elaborando ingeniosos sistemas cerrados que le protegen de las inclemencias del tiempo, donde se puede considerar que la ciencia le encierra en su interior.

El medio ambiente se encuentra liberado y se incorpora al sistema de fuerzas en los modelos de R. Le Ricolais, donde realiza un trabajo de campo. En los primeros análisis, los estudios estructurales están vinculados a los radiolarios, es decir, a un mundo de microorganismos que precisan del entorno, de recintos que dispongan de reservas para poder sobrevivir y a su vez, aportan la energía suficiente para que los elementos conectados vivan gracias a la cadena que forman. Dicha dependencia del entorno se puede observar en la estructuras aérea presentadas en el proyecto del puente o en la canalización submarina construida para el túnel bajo el Estrecho de Messina. Como en el mundo de la electricidad, todo lo que nosotros captamos en el ámbito de lo perceptible como manifestaciones vitales de las plantas y animales (>elementos conectados), sería del todo inimaginable sin las moléculas estructurales y las sustancias metabolizantes de los microorganismos (> corriente eléctrica), que constituyen el fundamento del desarrollo vital. Por ejemplo, las extrañas y delicadas estructuras de los radiolarios ahorran material mediante sistemas triangulares tridimensionales que separan la tensión y la compresión y remiten al modelo hexagonal de la red geodésica.

Este vínculo con los organismos primitivos describe el interés que despierta el problema del crecimiento y el carácter ineluctable de la espiral logarítmica. Y, finalmente, responde sobre la reproducción fija de los organismos vivos: la representación de las fuerzas sobre una red automórfica forma un automorfismo. Nuevamente, aparecen las relaciones de continuidad y de contigüidad, ya que el automatismo de la repetición de una red triangular debe corresponder al automatismo de la distribución de esfuerzos. Le Ricolais comenta que junto a la vida aparece el problema del crecimiento, y hasta ahora el hombre no ha sido capaz de construir máquinas capaces de crecer. Futuros proyectos de estructuras estudian alternar el uso de la última tecnología junto con el no-empleo de la misma, buscando un equilibrio entre un dominio del medioambiente y el abandono de todo control sobre el mismo.

\section{Imágenes}

Figura 1. Malla tetraédrica 1-4 (moléculas). R. B. Fuller, «The Card-board House», Perspecta, 1953 Figura 2. Cúpulas geodésicas 1-4 (modelos). R. B. Fuller, «The Card-board House», Perspecta, 1953. Figura 3. Un pez-volador. Un único continente. Un único océano (diagramas). R. B. Fuller, Dymaxion Map, 1954.

Figura 4. Cartografía 1-2 (mapas). B. Fuller, Dymaxion Map, 1954.

Figura 5. Distribución de energía 1-2 (pantallas). B. Fuller, Dymaxion Map, 1954.

Figura 6. Dymaxion Map. Doblar los bordes (maquetas). R. B. Fuller, Dymaxion Map, 1954.

Figura 7. Estrategia estratosférica (diagramas). R. B. Fuller, Dymaxion Map, 1954.

Figura 8. Malla tetraedrica Configuración del espacio definida por la relación 4/3, 2/3 y 7/6 (ejes). R. Le Ricolais, Starhex, Hexa, Trihex. 1962-68.

Figura 9. Puente colgante de tubo funicular con estaciones de descenso cada $500 \mathrm{~m}$ (aire). R. Le Ricolais, Projet de Sky-Rail, 1970.

Figura 10. El nivel de flotación está a 35m. bajo el nivel del mar y da una presión hidrostática de $3-5 \mathrm{~kg} / \mathrm{cm} 2$ (agua). R. Le Ricolais, Under Sea Transit, 1970.

\section{Bibliografía}

FULLER, R. Buckminster:

"Geodesic Domes" y "Fluid Geometry", 1944. En: Your private sky. R. Buckminster Fuller. The Art of Design Science.

Ed. Joachim Krausse y Claude Lichtestein, Lars Müller Publishers, 1999; p.354-392.

"The Cardboard House". En: Perspecta, Pensilvania, 1953, n²; p. 27-35.

"Vertical is to live, horizontal is to die", Architectural Design 1969, n 12; p. 660-662.

BARONI, Daniele; D’Avvia, Antonio: “R.B.F.” En: Ottogono, Milán, 1988, año 17, grupo IV, septiembre.

BOTTERO, María: "Abstracción científica y pensamiento concreto en la utopía de Buckminster Fuller”. En: Zodiac, Milan, 1969.

CANDELA, Félix; PÉREZ PIÑERO, Emilio; CALATRAVA, Santiago; ESCROG, Félix; PÉREZ VALCÁRCEL, Juan:. Arquitectura transformable, Textos de Arquitectura, Escuela Técnica Superior de Arquitectura de Sevilla, 1993.

LE RICOLAIS, Robert:

"Under Sea Transit". En: Architectural Design, 1970.

"Considerations sur la geometrie des radiolaires". En: Zodiac, AAVV: Light structures, Milan, (1973) n 22. Forma parte del texto enviado a "The International Conference on Space Structures», University of Surrey, September (1966), vol. "Space Structures", Ed. R.M. Davies, Blackwell Scientific Publications, Oxford y Edimburgo, 1967.

"The Trihex: New Pattern for Urban Space". En: Progessive Architecture, February 1968. 
"Á la recherche d'une mécanique des formes". En: AAVV: Lights Structures, Zodiac, Milan, 1973, n²2. Conferencia dada en el Palais de la Découverte el 7 de julio de 1965

MCHALE, John: R. Buckminster Fuller. Creadores de arquitectura contemporánea. Hermes, Madrid, 1962.

NEPOTI, Paolo: "Premessa a Le Ricolais". En: AAVV: Lights Structures, Zodiac, Milan, 1973, n²2.

OTTO, Frei: Cubiertas colgantes, Editorial Labor, Barcelona, 1968. Trad. Francisco Folguera.

Robert Le Ricolais. Visiones y paradojas. Catálogo exposición. COAM, Madrid, 1997. 
Biografía.

Cristina Jorge Camacho. Madrid, 1969. Arquitecta por la ETSA de Madrid desde 1995. Doctorado en el Departamento de Proyectos en 2003 (ETSAM, UPM). Beca de urbanismo Cehopu, Cedex. Profesora ayudante doctor en el Departamento de Proyectos Arquitectónicos en la Escuela de Arquitectura (ETSAG, UAH). Profesora contratada en Jardinería y Paisaje y Composición arquitectónica en SEK-IE University Segovia. Profesora invitada por la Facultad de Arquitectura y Urbanismo de TU Universitat de Graz, 2008, por la FAU de Campinas (PUCCAMP, São Paulo), Brasil, 1998 y por la FAU de Montevideo, Uruguay, 1997. Máster Internacional de Fotografía. Itinerario de Concepto y Creación en EFTI. Exposiciones colectivas de fotografía: MAP-11 Photo Toulousse, "Európolis" Terraza Círculo de Bellas Artes de Madrid, "Mínimos" Galería Cero Madrid, finalista libro "Folktales RM Editorial. Actividad profesional CJC Arq\&Paisaje, Proyectos de Pasaijismo Fundación de Alzheimer Reina Sofía, Nueva Sede Caja de Ahorros de Badajoz.

\section{Biography}

Cristina Jorge Camacho. Madrid, 1969. Architect ETSAM, Madrid1995. Phd 2003 Architectural Department (ETSAM, UPM). Urbanism Grant of Cehopu, Cedex. PAD, Professor of Architectural Project Department, Architectural School (ETSAG, UAH). Professor of Gardering and Landscape and Architectural Composition in the SEK-IE University Segovia. Visiting Professor in the Faculty of Urbanism and Architecturel of TU Universitat Graz, 2008, FAU of Campinas (PUCCAMP, São Paulo), Brasil. 1998 and FAU of Montevideo, Uruguay, 1997. International Master of Photography. Concept and Creation Itinerary of EFTI. Collective Exhibitions of Photography: MAP-11 Photo Toulousse, "Európolis" Terraza Círculo de Bellas Artes de Madrid, "Mínimos" Galería Cero Madrid, Finalist "Folktales" RM Editorial. Free-lance Studio CJC Arq\&Paisaje, Landscape Projects: Foundation Center Reina Sofía of Alzheimer, New headquarters of Caja Ahorros of Badajoz. 